\title{
An Exploration of Curriculum Reform of English Higher Education from the Perspective of Internationalization
}

\author{
Guan Beibei \\ Harbin Institute of Technology (Shenzhen), Shenzhen, 518000, China
}

Keywords: international perspective; English higher education; curriculum reform

Abstract: As for the purpose of English higher education, people also have different understandings. The author thinks that first of all, it emphasizes the persistence and cultivation of the university spirit, applies to teaching and scientific research, and promotes independence, suspicion, rigor and innovation; secondly, it must pay attention to the integrity of personality training and people. To live in harmony, properly or even skillfully deal with various relationships, show a kind of ultimate humanistic care for nature, society, and self; at the same time, moderately serve the economy in which we are located, this service must be structured in different ways, and colleges and universities should take different forms of service.

\section{Introduction}

In Chinese, "there is nothing less than a thousand miles away" fully illustrates the importance of the starting point and the foundation. Although all universities exist in a particular economy and political body and are inevitably affected by it, the nature of the university still has a strong commonality, which is also the core of the university and the foundation of survival. There is no doubt that the purpose determines the content and means. Therefore, the internationalization of English higher education serves the purpose of realizing English higher education. There are various forms of internationalization of colleges and universities in various regions of the world. After combing, the following aspects are mainly included [2].

\section{The internationalization of educational concepts}

The concept of education includes many things. The first is the concept of university. In history, the international community has always been interested in seeing why universities should be established. The wise see wisdom. It seems that from the beginning of the establishment of the university to today, there will always be this fact in the foreseeable future, and it can be assumed that the university has played its due function, otherwise there is no need to exist. The author attempts to summarize various viewpoints on the purpose of English higher education and points out that the purpose of English higher education is mainly to promote the university spirit, cultivate complete personality, and moderately serve the economy and society. Although different universities have different conditions and their own conditions are different, different universities have different focuses, but overall they are in line with the above-mentioned concepts. This is not a 
simple synthesis, but an inference based on systematic thinking on the complexity of English higher education itself as a functional system and its economic and social system, that is, the environmental system. I believe that only higher education in English This subsystem is put into consideration in the large system in which it is located in order to accurately grasp its nature and function.

\section{Teachers' Composition of English Higher Education Internationalization Curriculum Reform}

\subsection{The Influence of Outstanding Faculty on the Reform of English Higher Education}

The internationalization of the composition of teachers does not mean that the faces of several foreigners are added to the podium. Imagine if the people who stand on our rostrum are nationals, but they are all top international players in the same field. Do we still need foreign teachers? It is not necessary at least from an academic point of view. Of course, the reality is far from this, so we strive to obtain excellent teachers in an international perspective [1]. In China there is a cry of "prospering the hope of the nation in education and revitalizing the hope of education among teachers". In the United States, similar views were also put forward: "First, the success of the United States depends on the quality of higher education. Second, the key to success is to establish a professional team that is compatible with this task, that is, a well-educated the teachers' team is, of course, subject to various economic, political, and cultural factors, and it is unrealistic to require all teachers to be world-class. It is necessary to tailor them according to the actual situation and make their own teaching staff reasonable.

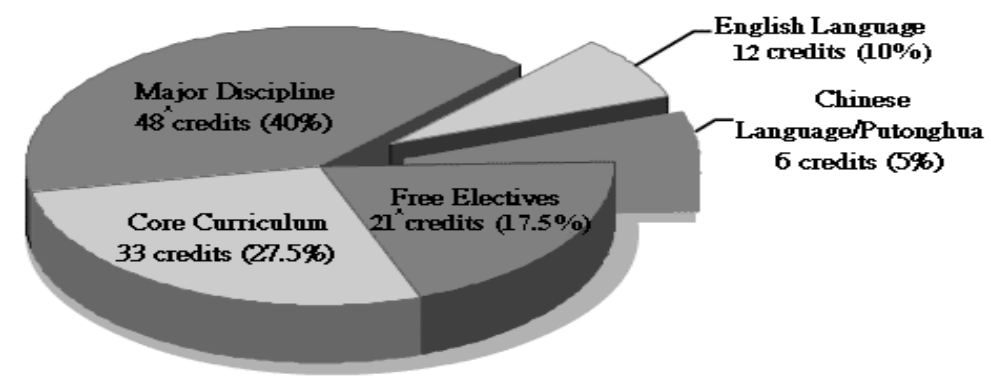

Fig.1 The share of English education in higher education

\subsection{Colleges and Universities Launch and Introduce Teachers of the Corresponding Specialty}

Introducing international first-class teachers directly requires strong financial support. This is unrealistic for many colleges and universities, but there are still many ways to learn from it. The use of limited funds to hire the most urgently needed international outstanding teachers, on the one hand, strives to make breakthroughs in a certain field, and on the other hand, it is necessary to maximize the use of the teacher. It is not to make it exhausted, but to try to get as many teachers as possible. As students benefit from their teaching and lectures, they must send their best key teachers as assistants of the teacher, learn in service, practice in learning, and strive to improve themselves. The result of this is often that a teacher can bring out a large number of outstanding young teachers. This is the school's wealth. Of course, if financial resources permit, sending teachers to study abroad, training, attending academic conferences or conducting cooperative research will have better results. This requires thinking in terms of system thinking. It is necessary to carry out elemental analysis as well as relationship analysis. Only in this way can it be possible to achieve a multiplier effect. 


\subsection{Cultivate Students' Subjective Initiative and Creativity}

Modern education pays more and more attention to students' subjective role and creativity. "Learn to survive" believes that "teachers' responsibilities are now passing knowledge less and less, and they are increasingly motivated to think. Apart from his formal functions, he will increasingly become a consultant and an exchange of opinions." The participants, one who helps find contradictory arguments rather than those who appear to be truthful, must concentrate more time and energy on engaging in effective and creative activities: mutual influence, discussion, motivation, understanding, encouragement ". Today's teachers need to be educational artists and need to complete the transformation from traditional teaching staff to modern teachers. Each student should be regarded as a precious resource - that is, a unique individual. His talent is to be discovered. His skills need to be improved. His mind needs to spur and nourish. This is a systematic requirement for teachers as a mixture of multiple roles [2].

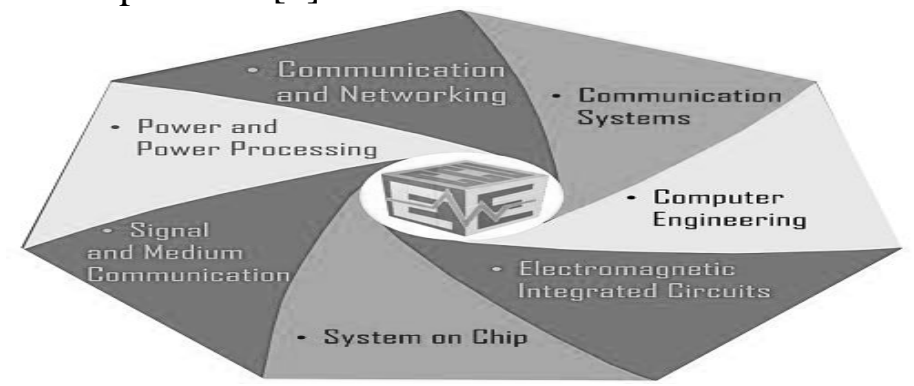

Fig.2 Correlation Diagram of College English Higher Education Reform

\section{Internationalization of Curriculum Settings}

\section{1 emphasis on language courses, use the original textbook}

The purpose of the internationalization of curriculum is to cultivate world-class talents that meet the development needs of the times. This requires us to objectively understand the role of language in this. Some people advocated Westernization and fully used English to teach classes. They thought that teaching was mainly conducted in English and internationalization was completed. Some people also think that our Chinese universities must adhere to teaching in Chinese, especially as China's economy is growing rapidly. More and more people are already interested in learning Chinese. The number of foreign students studying in China every year averages 20 - 30\% increase in speed.

\subsection{Opening International Courses to Train International Talents}

The purpose of setting up an international course is to help students understand the outside world and understand the cultural customs and customs of other places and peoples in the world in order to achieve what Mr. Fei Xiao tong's old man said: “The beauty of the United States, the beauty of beauty, the beauty and the common, the world Datong." The fifteen words of Mr. Fei Lao are an excellent explanation for the "gentleman harmony but different" and are also the best footnotes for the "harmony" concept and spirit advocated by the contemporary. International talents must first understand and respect the diversity of different cultures. International courses are just a carrier.

\subsection{Promoting Intermational Cooperation in Running Schools}

International cooperation in running schools is actually a short-term and fast approach to the 
internationalization of educational concepts, the internationalization of teachers, the internationalization of students, and the internationalization of curriculum settings. It can quickly and effectively promote the internationalization process. However, international cooperation in running schools cannot be achieved overnight. It should be conducted in a selective manner. In particular, the choice of partners should be cautious. The first thing to consider is whether or not the concept of running a school is the same or similar. This should be the key to making decisions. Because the cultivation of talents should be all-round, different concepts will lead to serious consequences.

\subsection{Internationalization of school conditions}

The internationalization of school conditions is mainly information. In addition to further strengthening the library's data query function, it is necessary to highlight the timeliness and convenience of international information transmission, build a digital campus, and encourage cross-school, inter-regional, and transnational Information Sharing. In fact, the author believes that the internationalization of school conditions is more important than the construction of soft environments. As shown below:

- Freedom of speech

- Academic authority.

- Loose academic atmosphere

\section{Summary}

To sum up, only using system thinking to understand, using system theory to analyze, put the English language higher education internationalization function system into the large system of English higher education, and consider putting higher education in English to where it is to live. To grasp the nature and content of the internationalization of English higher education in a comprehensive and accurate manner in order to properly play the role of the internationalization of English higher education and to discover the truly practical methods of implementing the internationalization of higher education in English.

\section{References}

[1] Wei L. Optimizing English Curriculum in Higher Vocational Education from the Perspective of Education Internationalization [J]. Science Education Article Collects, 2017.

[2] Bordilovskaya A. Internationalization of Higher Education in the Foreign Language Curriculum in Japan: A Teacher's Perspective on Compulsory English Discussion Course [J]. 2018. 